\title{
The Mallet Project: \\ from an earthquake laboratory to laboratories on the territory
}

\author{
Graziano Ferrari
}

Istituto Nazionale di Geofisica e Vulcanologia, Bologna, Italy

\author{
Article history \\ Received March 16, 2012; accepted April 16, 2012. \\ Subject classification: \\ 1857 Basilicata earthquake, Environmental education, Historical landscape, History of seismology, Robert Mallet.
}

\begin{abstract}
On December 16, 1857, an earthquake wreaked havoc across a huge area of the regions of Basilicata and Campania (Val d'Agri and Vallo di Diano). More than 180 villages in an area of over $20,000 \mathrm{~km}^{2}$ suffered very severe damage. More than 6,000 houses collapsed or became uninhabitable, and 19,000 people were killed. In the months of February and March 1858, the Irish engineer Robert Mallet undertook a mission to study the earthquake with a grant from the Royal Society of London. In 1862, he published his extraordinary study diary, in which the technical and scientific observations mingled with descriptive and literary details. This represents, from different angles, a unique 'observatory' over the landscape and the social, economic and cultural aspects of Val d'Agri and Vallo di Diano. In 2003, the Provinces of Salerno and Potenza started up a joint venture with the Storia Geofisica Ambiente of Bologna and with the scientific partnership of the Istituto Nazionale di Geofisica e Vulcanologia, with a view to setting up provincial laboratories dedicated to environmental education, and named after Robert Mallet. The Mallet Project proceeded up to 2009 on three agreements. Within the framework of the idea of a 'Mallet Laboratories' Project, there has been the opportunity to set up a network of study centers in the territories of these two provinces (Salerno and Potenza), which can promote research with great national and international breadth, starting with the world of schools and local communities. The study entitled Viaggio nelle aree del terremoto del 16 dicembre 1857 was published through the period from 2004 to 2009.
\end{abstract}

\section{Introduction}

On December 16, 1857, at around 10:15 pm, an earthquake devastated a vast area of Basilicata and part of Campania (southern Italy). The present-day province of Potenza and the central-eastern zone of the province of Salerno were hit in particular. The most serious damage occurred in the mountain areas, and mainly in Val d'Agri and Vallo di Diano. The most deaths were recorded for the villages of Montemurro, Grumento Nova, Viggiano, Tito, Marsico Nuovo and Polla. As a result of this shock and the numerous aftershocks, including destructive ones that followed, more than 180 villages over an area of more than $20,000 \mathrm{~km}^{2}$ suffered very serious damage to buildings, to the extent that most of the houses had to be abandoned. In this area, more than 30 centers suffered disastrous damage; whole towns and villages spread out across an area of $3,150 \mathrm{~km}^{2}$ were razed to the ground. Altogether, 3,313 houses collapsed and 2,786 became uninhabitable, and about 19,000 people died, with $90 \%$ of these in the Potenza Province (Figure 1) [Ferrari and McConnell 2005, Guidoboni et al. 2007, Burrato and Valensise 2008].

The Irish engineer Robert Mallet was a witness and an extraordinary 'scientific chronicler' of the effects of this earthquake. On January 27, 1858, Mallet left England to carry out research in the ruins of the mountain villages of Basilicata, supported by a grant worth 150 pounds from the Royal Society of London. From February 12 to March 1,1858 , he undertook a scientific mission to the areas most badly hit by the earthquake, drafting out an extraordinary diary in the process, in which his technical-scientific observations are combined with those that were more descriptive and literary (Figure 2).

An earthquake such as this one was the natural laboratory that Mallet had been waiting for, for over 10 years, to be able to test his theory on earthquake dynamics that he had presented at the Royal Irish Academy in 1846 [Mallet 1848]. The maturity of this research is indicated by some of his conclusions, which gave advice to deepen the studies in three fields: 1) surveying of damage caused by earthquakes according to a new series of criteria, to arrive at the origin of the disturbance; 2) study of the velocity of the elastic waves; and 3) installation of observatories for the study of earthquakes in some of the more exposed areas, so as to obtain "complete data relating to the moment of transit of the wave, and the breadth and height of the waves in particular regions".

The originality of the scientific method implemented by Mallet consisted in the systematisation and accurate fi- 


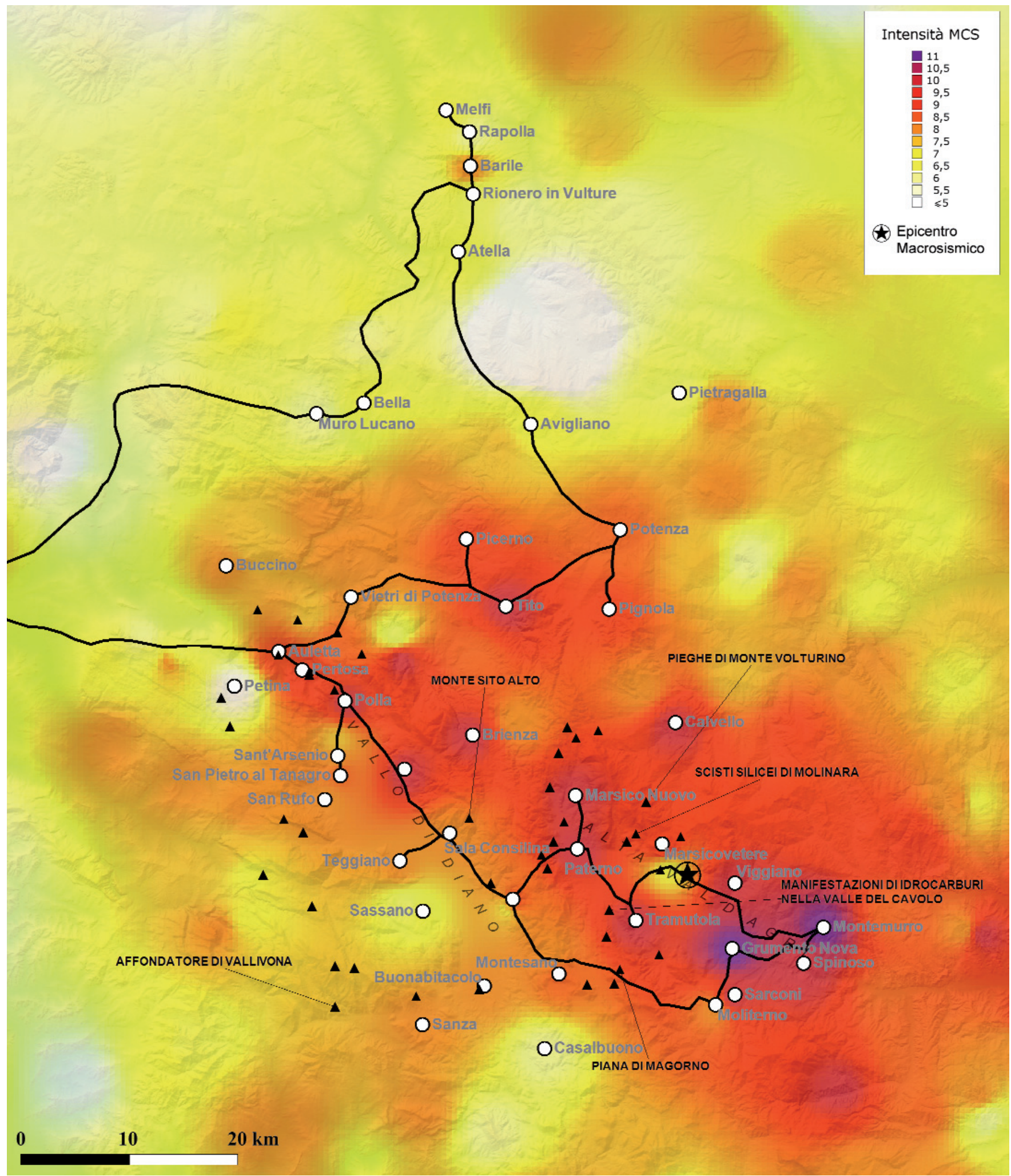

Figure 1. Summary map of the area struck by the earthquake and involved in the Mallet Project. Coloured patterns, black lines and black triangles represent the intensity distributions of the seismic effects (MCS scale), the path of Mallet's journey, and the locations of the geosites mapped during the Project, respectively.

nalization of observations of the earthquake effects, which had previously been used only partly with the aim of quantitative assessment. Upon his return to England, Mallet put his observations down in a weighty report, which he published in London in 1862, with the title: The Great Neapoli$\tan$ Earthquake of 1857. The First Principles of Observational
Seismology. With this title, Mallet gave a name to the nascent science of earthquakes: seismology.

However, this earthquake had another peculiarity, which was not a seismological one: it was the first earthquake where the effects were documented by photographic reportage, which consisted of over 200 photographs, most of which are 


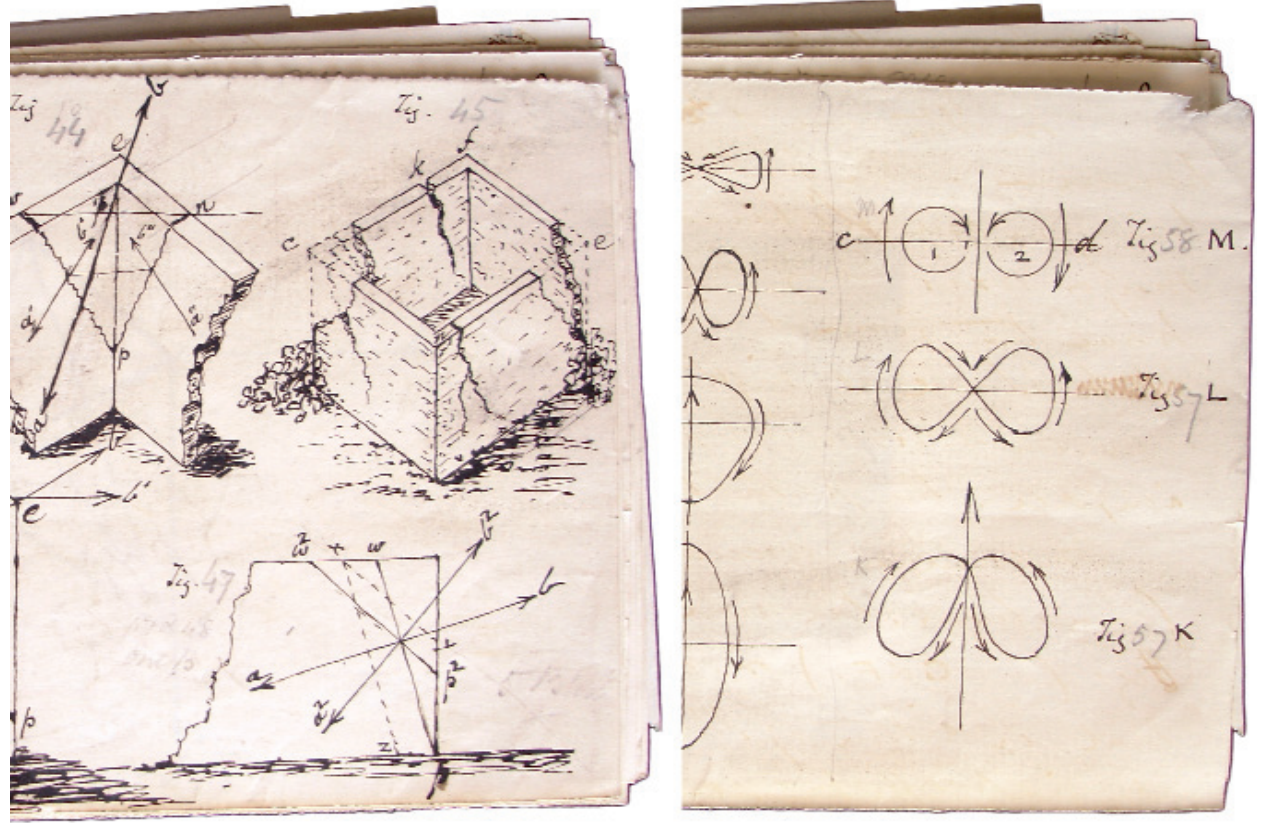

Figure 2. Particulars of the original drawings by Mallet to document the directions of the fractures in buildings having a rectangular plan hit by seismic waves (left), and the trajectories of the seismic-wave particles of different types (right).

stereoscopic. Between December 20, 1857, and May 1858, at least two photographers ventured into the territories devastated by this earthquake: Alphonse Bernoud, a famous French photographer who worked in Naples from July 1856, and Claude Grillet. Mallet commissioned photographic documentation of his study mission from Grillet (whom he calls Grellier in his report): 156 photographs (Figure 3), 120 of which are stereoscopic and 36 monoscopic, which were used by Mallet to document his own scientific speculations when they were published in his large report cited above.

From different standpoints, this report by Mallet on

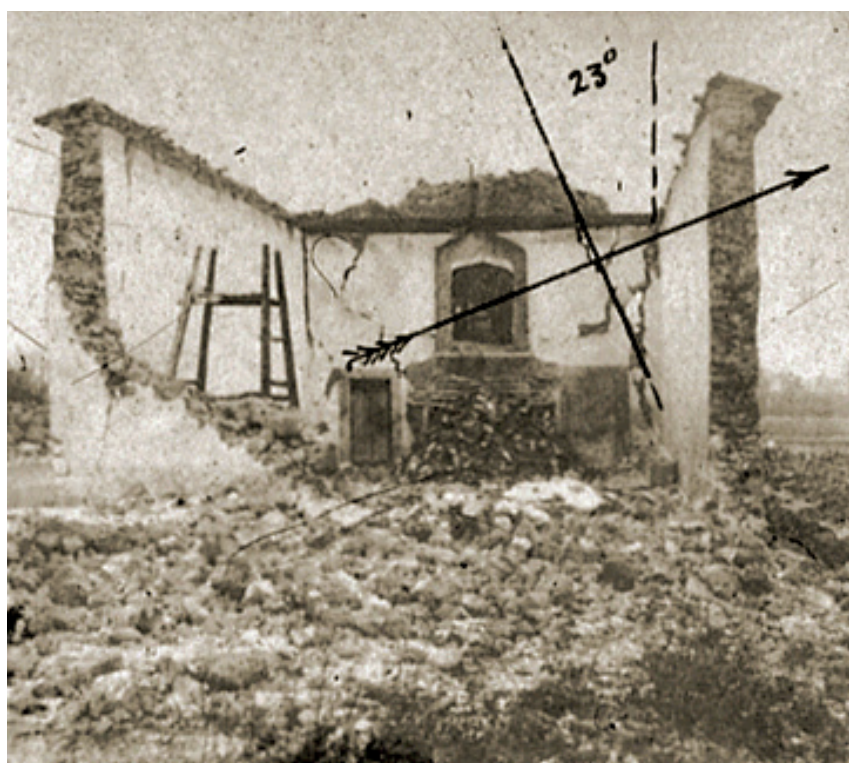

Figure 3. Church of the Trinity at Trinità di Sala Consilina (province of Salerno). Left photogram of one of the stereoscopic photos commissioned by Mallet. The pen lines superimposed by the Irish engineer contribute to the attribution of the photograph to Claude Grillet. the 1857 earthquake also represents a unique 'observatory' on the landscape and the various social, economic and cultural aspects of the areas that were worst hit by the earthquake. In spite of the dramatic impact that this earthquake had on the territory, the contact with the population leaving there showed that the memory of this event was poor, or almost nonexistent, within the population of this region. In contrast, the Irpinia earthquake of November 23, 1980 (M 6.9), was an emphatic reminder of this terrible event, even if it only 'lapped' the northern part of the area that had already been affected by the earthquake of 1857, with some further damage and destruction.

The part of the territory of the provinces of Salerno and Potenza that was hit by the earthquake had been one of the few parts of the Mediterranean area that had kept its natural and cultural legacy intact and integrated into the economic and social structure. As a result of this ancient 'harmony', this area offered a unique opportunity to create a privileged 'observatory' over its natural environment, as well as its historic and present-day anthropology, which was finalised to fostering the conscious participation of the inhabitants of the area in the territorial context.

In this territorial context, towards the late-1990's, new challenges started to take shape between two apparently irreconcilable demands: development and quality of life. For the two Provinces of Salerno and Potenza, among the many practical cases, there was also that of the tragic flood of River Sarno on May 5, 1998, and that of the development of the extractive oil industry in Val d'Agri. Only recently has the dynamic equilibrium between these two aspirations encountered the prospect of sustainable development. Within the framework of the idea of a 'Mallet Laboratories' Project, there has been the opportunity to set up a network of study centers in the territory of the two provinces, to promote research characterised by great national and international breadth, starting with the world of schools and local communities.

\section{The Mallet Project}

At the beginning, the main objective of the Mallet Project was to increase the sensitivity of the resident population of the Salerno and Potenza provinces, and in particular of the areas affected by the destructive effects of 
the 1857 earthquake. It was also designed to prevent the risks associated with natural catastrophes, such as earthquakes, landslides and floods, and to educate a new culture of security.

Despite many bureaucratic difficulties, the Project officially started in 2003 , as a concrete sign that strategies promoting research and environmental education were being achieved. These aspects are indeed of great importance in the drafting and the enforcement of plans for safeguarding the territory, in which the regional administrations of the Italian State, first and foremost the Regions and the Provinces, are increasingly called upon to operate.

The Project has involved 52 municipalities of the provinces of Salerno and Potenza (all of the Alta Val d'Agri, the Vallo di Diano, the Valle del Bradano, and the Vulture), and since its beginning there have been three main phases envisaged: (i) the creation of a publication as a bib- liographical point of reference and awareness; (ii) the realization of initiatives of dissemination at all levels of society; and (iii) the design and creation of the Mallet Laboratories, to provide education in sustainable development. The first two phases have continued over the duration of the Project, as described here (2003-2009), while the third phase was launched in 2007, and is still in progress.

At the beginning of the Project, there were no predefined guidelines to achieve the main goal, but priority was given to the knowledge of the territory, which was followed as the same journey that Mallet made 150 years ago. We tried to be in 'contact' with the local people, to understand the different cultures, and to find the best language in which to communicate. So, indirectly, and sometimes directly, the recipients of the objectives of the Project became involved in the construction of the Project itself, and in the construction of the communication process.

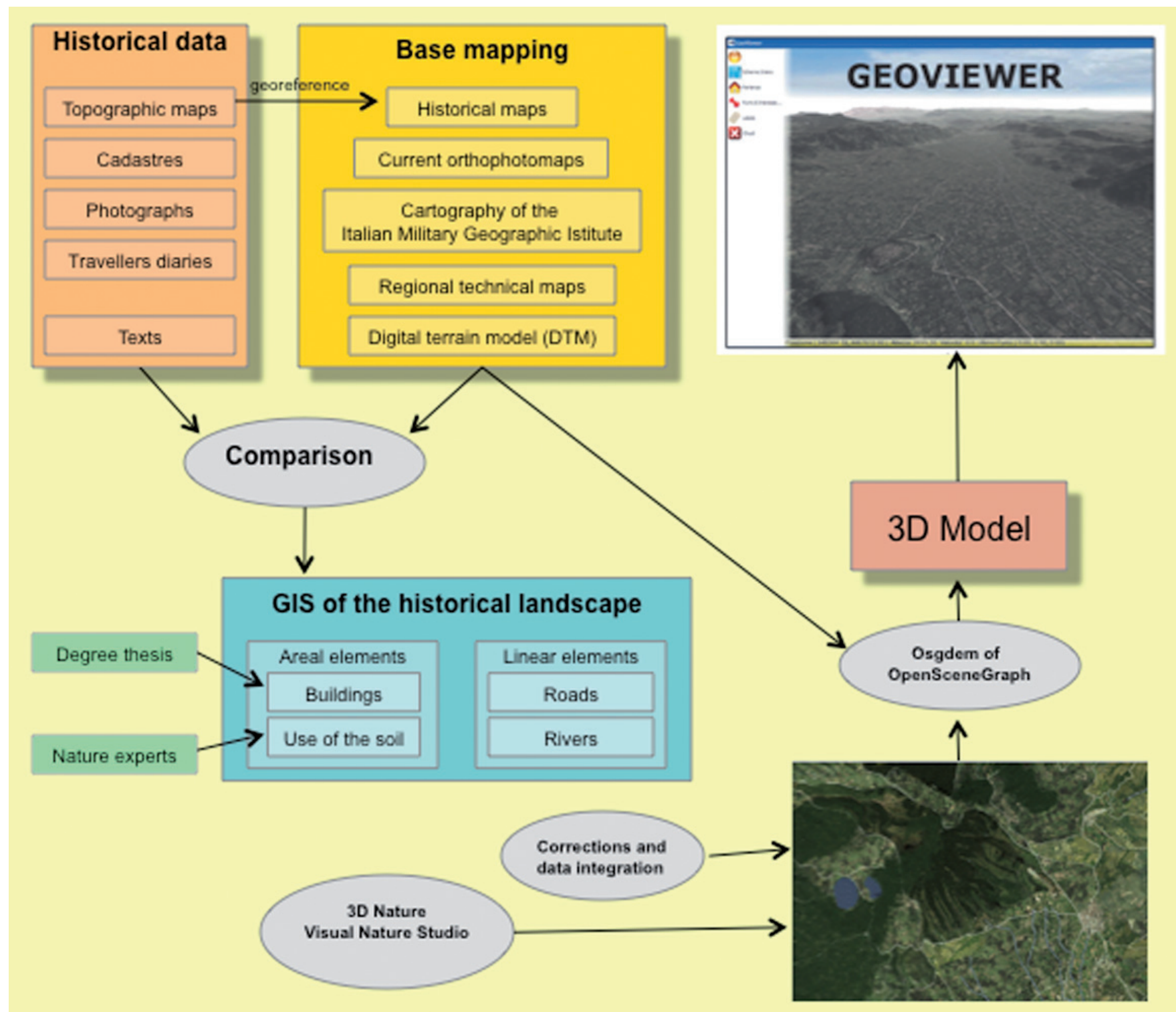

Figure 4. Scheme of the work phases that led to the realisation of the virtual historical landscapes for the three-dimensional navigational software GEOviewer. 


\subsection{Publications}

The publishing activities started in 2003, with two volumes and a multimedia DVD-ROM, which have since been extended to a further four volumes and two updates of the multimedia product. The great narrative value of Mallet's work produced the idea of a virtual journey into the territories hit by the earthquake. To achieve this, it was necessary to create a high-immersion environment by means of multimedia instruments, while rigorously adhering to the historical reality of the mid-eighteenth century in the area of Lucania.

Thus, a thorough research phase was started, for the territorial and historical environmental data for the reconstruction of the historical landscape of the area, on a scientific basis. This reconstruction, which at the beginning appeared to be a sub-product of the Project, soon became one of the main development sectors of the Project itself. The true novelty was not the reconstruction of realistic virtual landscapes, a practice already in use for some years and that has been undergoing development in Italy in several professional and scientific sectors. Rather, it was that this reconstruction occurred on the grounds of a complex global information system (GIS) that was filled with historical data that were retrieved and processed, starting from the cross-matching of different types of sources (Figure 4). During the second phase of the Project, in 2005-2007, an original interactive system was also developed in the historical landscape thus constructed.

A thematic library was built in the area that comprises around 800 original texts, and territorial reconnaissance was performed for over 5,000 hours across an area of some $3,200 \mathrm{~km}^{2}$, that is populated by over 350,000 people. In the most operational part of the Project, the Irish scholar's itinerary was retraced several times not only 'in the territory', but also in the stories of the land, the water and the people. Here we sought the persistence and the changes with respect to what Mallet had described or reasonably seen in these lands. Following in the tracks of Mallet and the two photographers, Bernoud and Grillet, we looked for, and where possible found, the places described and photographed by these particular travellers. Through the collaboration of technicians, scholars and private citizens, we identified the points where the photographs were taken, and we reproduced the same shots. This enabled us to highlight the changes and the persistence in the natural and anthropised landscape (Figure 5) as well as to correct some errors made by Mallet in identifying the places that were photographed. By his own testimony, the Irish engineer received Grillet's photographs very late, without any indication of the subjects and the places photographed, and so he found it very hard to reconstruct them from memory.

Interviews were carried out using both audio and video, into aspects of the territory, the history, and the popular culture. The Project is immersed in the cultural identity of these populations.

The guiding idea is that the Project should represent a broad cultural catalyzer, without however forgetting the pivot on which Mallet's scientific activity revolved: the earthquake. Therefore, by analyzing the earthquake as part of an environment, both natural and anthropic, from these effects of the earthquake, a mature society can draw useful elements for a new culture based on safety.

Overall, the publication is made up of six volumes and three multimedia DVD-ROMs [Ferrari 2004-2009]. Volumes 1, 3 and 5 collected together 44 original contributions that deal with issues and aspects of the natural and inhabited territory, and that are also very different. Volumes 2 and 4 collected the reproductions of the historical sources, such as the unabridged Italian translation (vol. 2) of Mallet's work [Mallet 1862] or the facsimile reproductions, with transcripts of the official handwritten documentation of the Kingdom of Naples relating to the expeditions of Mallet, Bernoud and Grillet (vol. 4).

Volume 4 also contains the facsimile reproduction of the original handwritten manuscript of the lavas collected by Mallet in his subsequent mission to study the Italian volcanoes in 1864 . The decision to publish reproductions of these handwritten documents that come from Italian and foreign public archives, was to draw in nonspecialist readers, as well as to reveal the value of the unpublished documentary heritage of which Italy is so rich. The fact that the historical documentation is elaborated within an important seismological discipline, historical seismology, contributes in a major way towards the mapping of the seismic hazard of the Italian territory. This has enabled us to underline that apart from being an operation of great historical and cultural value, the saving of our documentary assets is rather like a sort of 'life insurance.'

Lastly, volume 6 re-elaborates in a summary and thematic manner the contents of the first five volumes, and it represents an iconographic index of the rest of the series. Many references in the text refer both to the other five volumes for further analysis, and in a sort of hypertextuality, to specific parts of the same five volumes.

The DVD-ROM is now in its third release, and it has developed a complex virtual journey in the territory and in time, following the tracks of Robert Mallet, in the area most damaged by the 1857 earthquake: the lands, the waters and the peoples of these two valleys. We chose to deal with the aspects relating to the Project topic in the form of microhistories, suggestions, details of an imaginary trip, short yet intense in the history, the environment and the culture of the Val d'Agri and the Vallo di Diano. This is a journey realised with the involvement of government institutions, and those of the coordination, i.e. the village and Mountain Communities administrations. However, 


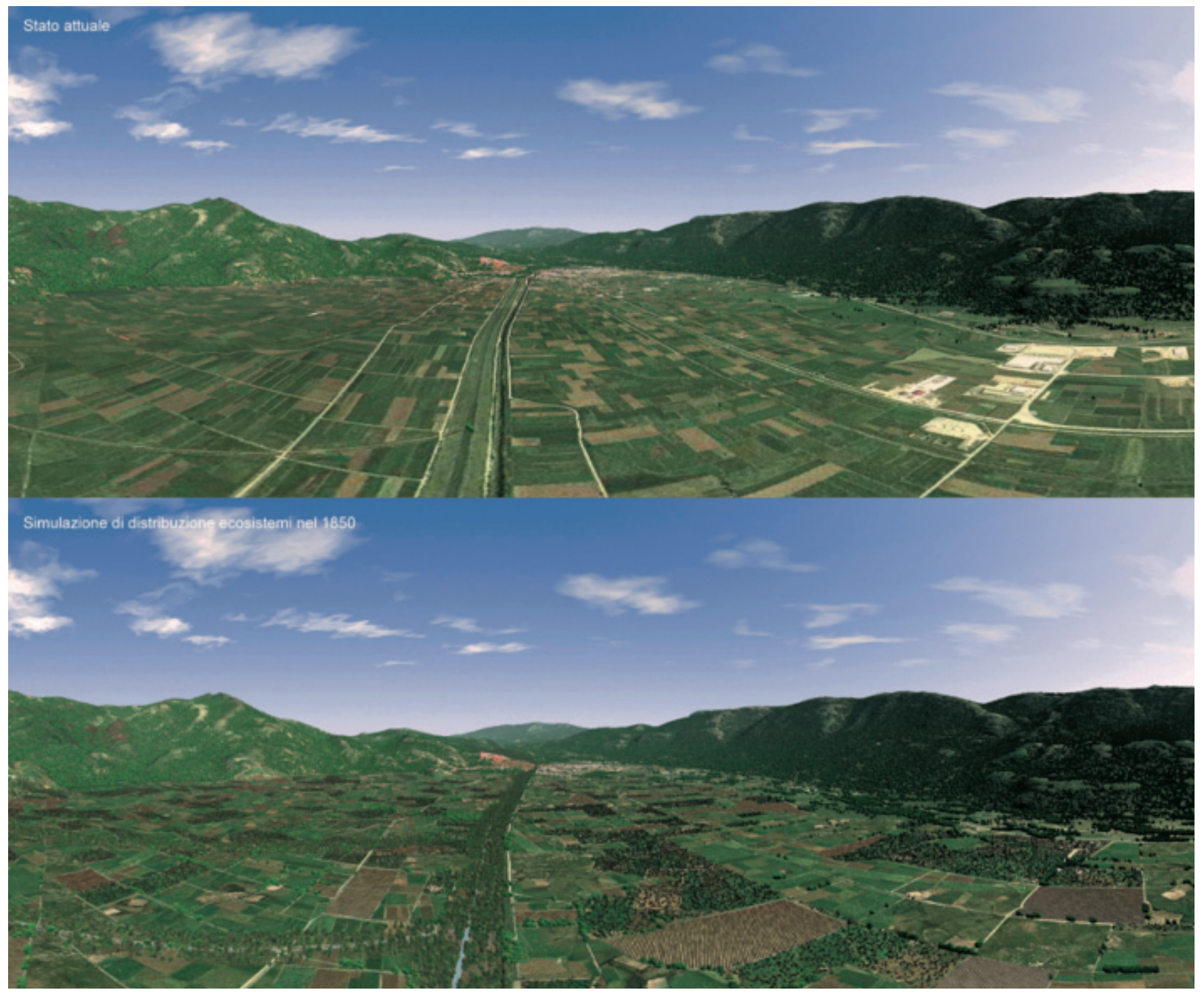

Figure 5. Comparison between the landscape of the Vallo di Diano today (above) and the virtual one of the middle 19th century (below).

above all, it involves the people, many of whom were eager to collaborate on this Project, which they experienced so intensely. Several schools of the area have also contributed to the contents of the stories on the DVDROM, with school projects performed on various aspects of the natural and inhabited territory, thereby taking part in a direct way in the cultural production.

The DVD-ROM thus tells the story of this territory, its geology, its geodynamics, its natural risks, its traditions and its cultural identity and history. Over 2,500 stories of the water, the land and the people, as 3 hours of a virtual journey like that made by Robert Mallet and by the other witnesses of the effects of the earthquake. There are also over 10,000 images, mostly from territorial reconnaissance, 450 animations and films, and 45 thematic pathways.

\subsection{Realization of the dissemination initiatives}

The Mallet Project has kept constant contact with the various components of civil society of the area, both for the research, study and cultural production phase, and for the specific moments of dissemination of the results of the Project.

All of the Project activities have been promoted and documented through a website (www.malletlab.it), which soon became the point of reference for the schools and cultural associations that are involved in the Project and that have been affected by its repercussions.

The targeted distribution of the volumes of the publication to the libraries of all of the municipalities involved in the Project has been one of the strengths of the dissemination module of the Project. These dissemination initiatives have involved both the inhabitants of the different villages and the school-going population. Furthermore, each year, close to the date of the earthquake (December 16) and for the whole duration of the Project, dissemination activities have been organised on the various aspects dealt with in the volumes, in both Alta val d'Agri and Vallo di Diano (in general, in the Certosa of Padula), and in Vulture.

In December 2007, on the occasion of the 150th anniversary of the earthquake, a series of events were or- 
ganised with educational, scientific and cultural natures, along with an opening concert of nineteenth century music on the theme of Nature.

In 2006, the Project was presented in Dublin, upon invitation, at the Italian Institute of Culture and at the Dublin Institute of Advanced Studies. The latter initiative fostered the knowledge of Mallet in the Irish geophysical world in which he was practically unknown.

With the publication of the last box-set with volumes 5 and 6 , the first phase has been completed and the dissemination module has entered its more mature phase. Volume 6 has been printed as over 2,500 copies in a paperback version, for distribution to the secondary school students of the territory involved in the Project. The numerous hypertext links from volume 6 to the other five volumes, as mentioned previously, stimulate the students to analyse in greater depth the topics that are summarised in volume 6 .

\subsection{Design and creation of the Mallet Laboratories for Education in Sustainable Development}

The aims that we wanted to achieve were clear from the start, at least on a macro-scale, with the realization of the Mallet Laboratories for Education in Sustainable Development. However, it was only in the course of the Project that it was possible to outline more accurately the structural, operational and communication model of the laboratories that were to be set up. This was accomplished through the analysis of the specificities of the territory studied and described, with an understanding of its environmental and cultural vocation.

During the intense activity of territorial reconnaissance, the great wealth of the cultural producers was assessed: e.g. of individual scholars and associations. Most of these protagonists of the local cultural production operate in isolated ways, and so the idea has been to bring them together within a sort of cultural network. Thus, along the lines of the far more famous academy that funded Mallet's original expedition, this network can function as a cultural catalyst and as a point of reference for the Mallet Laboratories, as the 'Mallet Virtual Academy'.

The Mallet Laboratories were first of all intended as a center of cultural aggregation for the environmental, historical and ethno-anthropological issues of the area. It would have its own center of documentation and point of consultation for the publications of the Mallet Project. The activities of the Laboratories are oriented towards developing training and information. Indeed, the central fulcrum around which the individual actions provided for in the Mallet Laboratories Project is the involvement of the local population in the environmental education and information processes. Specific collaboration was planned with the schools in the territory, both primary and sec- ondary, as well as with the cultural associations, where their specific aims are to address sustainable development and environmental protection.

After a first start-up phase, the users themselves became the protagonists of the actions of the Mallet Laboratories: the teachers and the cultural workers, such as leaders of study groups consisting of students and the local population. Then there are the students, teachers, cultural operators, researchers and local population as the producers of the content that contributes to the enriching the digital archive.

The sectors of activity in the training and informational fields include:

- environmental research into the different territorial ecosystems and biodiversities;

- enrichment of the contents of the web portal for the Mallet Laboratories, on the cultural, environmental, historical and ethno-anthropological aspects of the territory; - setting up and endowment of a library and a specialised media library;

- monitoring artistic and natural emergencies;

- didactic syllabus design;

- production of teaching and dissemination materials;

- dissemination and training on seismic risk, the earthquakes, and the constructions in seismic areas;

- creation and updating of the archives of knowledge and memories;

- periodic meetings, seminars, congresses and exhibitions and events;

- observatory on alternative energy;

- network with the school institutions, and with public and private institutions;

- promotion of the Mallet Project, of its activities, and its products.

The foundation of the first two laboratories, one in Sala Consilina (in the province of Salerno) and the other in Potenza, has allowed us to work actively on the increase in value of the geological sites of special value, and to develop educational courses (teaching methods) for their study for high school students. Some of these geosites were published as the geosites in Tarabusi and Lizza [2009].

\section{Conclusions}

This all started from one of the most destructive earthquakes in the seismic history of southern Italy that occurred on December 16, 1857, and the subsequent study mission undertaken by Robert Mallet. Then, almost 150 years later, the idea was born to develop an educational project for sustainable development in the present-day territories that at that time were devastated by the earthquake: the Mallet Project.

As well as the issue of the earthquake and its economic and social implications, and of the aspects linked 
to seismic risk and its prevention, a broad range of cultural, historical and ethno-anthropological issues have been developed.

The Project has involved 52 municipalities of the provinces of Salerno and Potenza, over an area of over $3,200 \mathrm{~km}^{2}$, populated by over 350,000 people, and it has been carried out with the financial support of the two provincial administrations.

A complex and articulated editorial project has also been carried out, consisting of six volumes and three multimedia DVD-ROMs that represent the knowledge base of the Project. These contain 44 contributions on historical, scientific and environmental matters, as well as a substantial corpus of published sources and manuscripts. The Mallet Laboratories have subsequently been developed with the involvement of the world of schools and all of the individual and associated cultural producers. All of these activities have been accompanied by numerous dissemination activities that have involved a very large part of the population that resides in the territory of the Project.

The Mallet Project started with the target of prevalently spreading the issue of natural hazards, and it has gone on to characterize the rising involvement of the population, of the administration, of the scholars, of the cultural producers, and of the schools to achieve these objectives. It has also been possible to develop and transfer to different citizens at different levels the analysis of the scientific, cultural and environmental identity, which are the peculiarities of the identities of these populations. In particular, we found that the results obtained have contributed to enhancing a sense of cultural identity between the two valleys, which has been recalled on a number of occasions by the scholars.

Furthermore, as the Project has been followed very closely by the political administrators of these territories, this has also served to stimulate the citizens' knowledge, with a view to asking the politicians the right sorts of questions. All too often, the politicians ask themselves questions and give themselves their own answers: answers that are often distant from the real needs of the citizens, or that the citizens, being unprepared, often fail to understand.

\section{References}

Burrato, P., and G. Valensise (2008). Rise and fall of a hypothesized seismic gap: source complexity in the Mw 7.0 16 December 1857 southern Italy earthquake, B. Seismol. Soc. Am., 98, 139-148; doi:10.1785/0120070094.

Ferrari, G., ed. (2004-2009). Viaggio nelle aree del terremoto del 16 dicembre 1857, (six vols. and three DVDROMs), Bologna, SGA Storia Geofisica e Ambiente.

Ferrari, G., and A. McConnell (2005). Robert Mallet and the 'Great Neapolitan Earthquake' of 1857, Notes and Records of the Roy. Soc. of London, 59, 45-64.

Guidoboni, E., G. Ferrari, D. Mariotti, A. Comastri, G.
Tarabusi and G. Valensise (2007). CFTI4Med, Catalogue of Strong Earthquakes in Italy (461 B.C.-1997) and the Mediterranean Area (760 B.C.-1500), website: storing.ingv.it/cfti4med/.

Mallet, R. (1848). On the Dynamics of Earthquakes; being an attempt to reduce their observed phenomena to the known laws of wave motion in solids and fluids, Trans. Roy. Irish Acad., 21, 50-106.

Mallet, R. (1862). The Great Neapolitan Earthquake of 1857, The First Principles of Observational Seismology, 2 vols, London, Chapman and Hall.

Tarabusi, G., and C. Lizza (2009). I geositi del Vallo di Diano e dell'Alta val d'Agri, In: G. Ferrari (ed.), Viaggio nelle aree del terremoto del 16 dicembre 1857, (six vols. and three DVD-ROMs), Bologna, SGA Storia Geofisica e Ambiente, vol. 5, 285-322.

Corresponding author: Graziano Ferrari, Istituto Nazionale di Geofisica e Vulcanologia, Bologna, Italy; email: graziano.ferrari@bo.ingv.it.

(C) 2012 by the Istituto Nazionale di Geofisica e Vulcanologia. All rights reserved. 